\title{
Soil tillage energy efficiency increase
}

\author{
Alexander Petrov, Yuri Saveliev, Pavel Ishkin*, and Mikhail Petrov \\ Samara State Agrarian University, 446442 Kinel, Samara region, Russia
}

\begin{abstract}
Tillage energy efficiency increase is one of the important tasks in improving the profitability and sustainability of agricultural production. The paper proposes to increase cultivation energy efficiency due to the use of traction-drive tilling implement with active working bodies, not creating a high traction resistance and not requiring a large towing weight of aggregated tractor. The analysis of the energy efficiency of soil cultivation using traction-driven tilling implements with active working bodies has been carried out, and theoretical dependences of the coefficient of efficiency of a traction-driven machine-tractor unit has been obtained. The possibility of increasing the efficiency of the unit by reducing slipping of the tractor wheels and losses on rolling of the unit has been determined, which has been achieved by transferring part of the power through the power take-off shaft (PTO) of tractor to the drive working bodies of tilling implement, which compensate for traction resistance of the implement and create a pushing force, reducing the resistance to rolling.
\end{abstract}

\section{Introduction}

The energy efficiency of agricultural production is largely determined by the energy efficiency of each process. In plant growing the most energy-intensive operations include soil tillage, which accounts for $40 \%$ of energy costs throughout the technology [1, 2]. In this regard, relevant and meaningful are studies aimed at optimizing the technological parameters of machine-tractor units, allowing more efficient use of energy resources in plant growing.

Tillage efficiency increase is possible due to the use of traction-drive tilling implement with active working bodies, not creating a high traction resistance and not requiring a large towing weight of aggregated tractor [25].

\section{Objects of research}

To increase the efficiency of tillage traction-drive tillage implement was developed (1), having a low traction resistance. The reduction of tillage implement traction resistance was achieved by transferring the main part of the power consumed by the instrument on the process of loosening the soil through the power take-off shaft (PTO) of the tractor to drive rotary working bodies which in turn create a pushing force, minimizing tractive resistance of tilling implement [6]. Most full energy efficiency of the traction-driven machine-tractor unit reflects such parameter as the coefficient of efficiency of the machinetractor unit (CoE MTU). This parameter depends on the process, machine design, drive wheel system, weight of the unit, tillage regimes and other constructional and technological parameters.

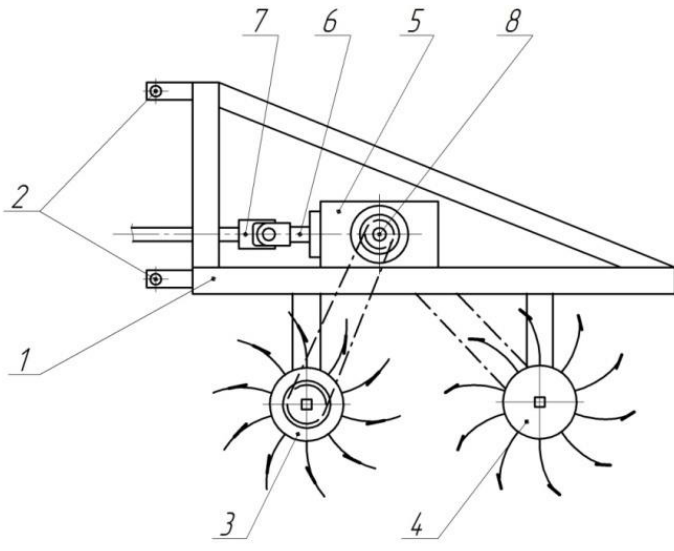

Fig. 1 Traction-drive tillage implement: 1 - frame; 2 attachment; 3.4 - needle disks; 5 - conical gear; 6 - input shaft; 7 - driveshaft; 8 - output shaft

CoE MTU shows how fully the effective power of the tractor is used under the soil technological treatment process and allows identifying ways to improve it by optimizing the constructional and technological parameters of traction-driven machine-tractor unit [7, 8].

\section{Results of theoretical research}

The coefficient of efficiency of the machine-tractor unit can represent a formula:

$$
\eta_{m t u}=\eta_{t r} \cdot \eta_{t i}
$$

where $\eta_{m t u}-$ coefficient of efficiency of the machine tractor unit;

$\eta_{t r}$ - coefficient of efficiency of the tractor;

$\eta_{t i}$ - coefficient of efficiency of the tillage implements.

\footnotetext{
* Corresponding author: ishkin_pa@mail.ru
} 
It is established [9] that the coefficient of efficiency of the tractor in traction-drive mode can be presented by the following formula:

$$
\eta_{t r}=\eta_{e w s} \cdot(1-\delta) \cdot\left(1-\frac{F_{r o l}}{F_{t t}}\right) \cdot\left(1-K_{p t o}\right)+\eta_{p t o} \cdot K_{p t o}
$$

where $\eta_{\text {ews }}$ - coefficient of efficiency of torque transmission from tractor engine to drive wheel shaft (coefficient of efficiency of tractor transmission);

$\delta$-slipping wheels of the tractor;

$F_{r o}$ - force of the tractor rolling resistance on the field, N;

$F_{t t}$ - tangential traction force by the torque on the wheel of the tractor, $\mathrm{H}$;

$K_{\text {pto }}$ - proportion of useful power of tractor engine, transmitted on the PTO shaft;

$\eta_{p t o}$ - coefficient of efficiency of the torque transmission from the engine tractor PTO shaft (coefficient of efficiency of the tractor PTO).

It has been also found [9], that coefficient of efficiency of traction-drive tillage implement can be presented by the following formula:

$$
\eta_{t i}=\left(1-\frac{M_{i m}}{M_{p t o}}\right) \cdot\left(1-\frac{h_{d}}{r_{d}}\right) \cdot\left(1-\frac{\mu \cdot\left(G_{t i}-F_{y}\right)}{F_{p u l}}\right)
$$

where $M_{\text {pto }}$ - torque on the PTO of the tractor transmitted to the traction-drive tillage implement in the work;

$M_{\text {im }}$ - torque to the tractor PTO transmitted to the traction-drive tillage implement in the idle mode;

$h_{d}$ - depth loosening rotary working bodies, $\mathrm{m}$;

$r_{d}$ - outer radius of disc working bodies, $\mathrm{m}$;

$\mu$-rolling resistance coefficient of supporting wheels;

$F_{p u l}$ - pulling force generated by the tractor, N;

$G_{t i}$ - weight of traction-drive tillage implement, N;

$F_{y}-$ vertical component of ground reaction, N.

Thus, the coefficient of efficiency of traction-driven machine-tractor unit represented by the formula:

$$
\begin{aligned}
& \eta_{m t u}=\left[\eta_{\text {ews }} \cdot(1-\delta) \cdot\left(1-\frac{F_{r o l}}{F t t}\right) \cdot\left(1-K_{p t o}\right)+\eta_{p t o} \cdot K_{p t o}\right] \times \\
& \times\left(1-\frac{M_{i m}}{M_{p t o}}\right) \cdot\left(1-\frac{h_{d}}{r_{d}}\right) \cdot\left(1-\frac{\mu \cdot\left(G_{t i}-F_{y}\right)}{F_{p u l}}\right)
\end{aligned}
$$

A calculation formula (4), represented as a graph, where the argument is selected component $K_{p t o}-$ the proportion of transmitted power through the tractor PTO (see Fig. 1). In the formula (4) the following values have been substituted: the coefficient of efficiency of tractor transmission $\eta_{\text {ews }}=$ 0.877 ; slippage of the tractor wheels $\delta=0.08$; force of the tractor rolling resistance on the field $F_{\text {rol }}=5258 \mathrm{~N}$; tangential traction force by the torque on the wheel of the tractor $F_{t t}=8119 \mathrm{~N}$; coefficient of efficiency of the tractor PTO $\eta_{p t o}=0.94$; torque to the tractor PTO transmitted to the traction-drive tillage implement in the idle mode $M_{i m}=$ $30 \mathrm{Nm}$; torque on the PTO of the tractor transmitted to the traction-drive tillage implement in the work $M_{p t o}=400 \mathrm{Nm}$; depth loosening rotary working bodies $h_{d}=0.06 \mathrm{~m}$; outer radius of disc working bodies $r_{d}=0.275 \mathrm{~m}$; rolling resistance coefficient of supporting wheels $\mu=0.16$; weight of traction-drive tillage implement $G_{t i}=3434 \mathrm{~N}$; vertical component of ground reaction $F_{y}=1030 \mathrm{~N}$; pulling force generated by the tractor $F_{p u l}=6500 \mathrm{~N}$.

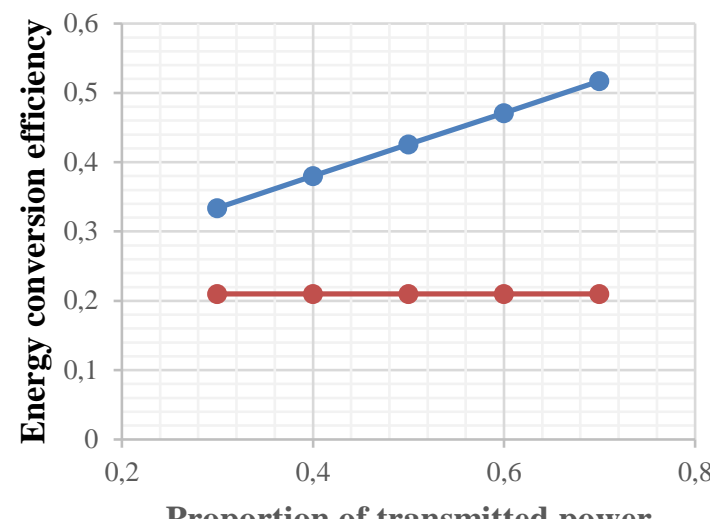

Proportion of transmitted power through the PTO

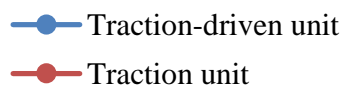

Fig. 2. Theoretical dependence of the conversion efficiency of mechanical energy from the engine to the work of loosening the soil depending on the proportion of power transmitted on the working bodies via the tractor PTO

The analysis of graphical dependence (Figure 2) allows concluding that increase of the proportion of power transmitted via PTO of the tractor during the operation of the traction-driven machine-tractor unit allows increasing efficiency of conversion of the mechanical energy of the tractor engine into mechanical work of loosening the soil. Calculations show that the transmission of half power via the tractor PTO allows a 2-fold increase of a coefficient of efficiency of traction-driven machine-tractor unit as compared to traction one.

\section{Methods of experimental research}

The energy evaluation of an experimental traction-drive tillage implement "TPO-3" was conducted for experimental verification of the obtained theoretical dependencies (Fig. 3).

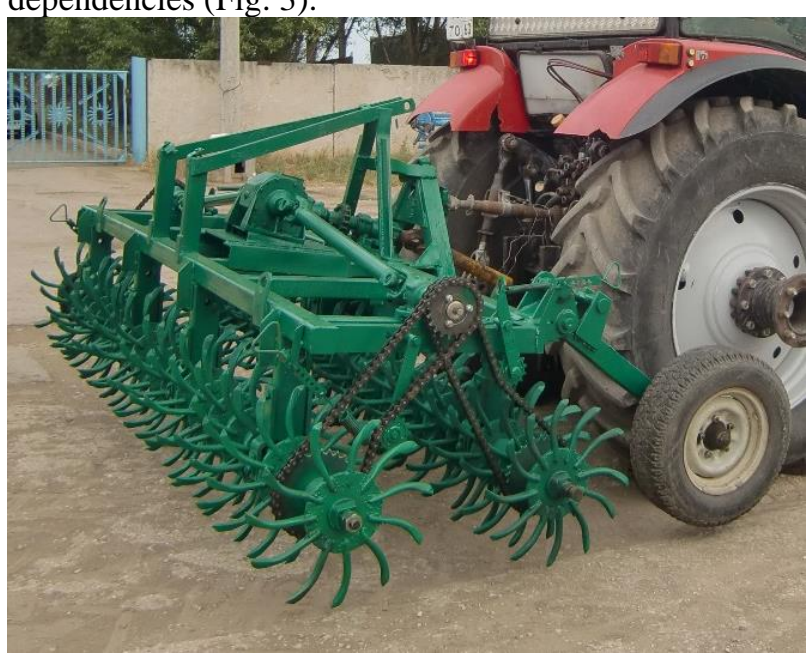

Fig. 3. Experimental traction-drive tillage implement "TPO-3" for early spring surface cultivation 
The methods of assessing the efficiency of operation traction-driven machine-tractor unit included a series of experiments during the early spring soil treatment with different gears (speeds motion) and estimation of the following parameters of the unit: the speed of forward unit movement, tractive resistance tillage implement, fuel consumption and slipping driving tractor wheels.

The power component for self-propulsion of the tractor was determined by towing (Fig. 4).

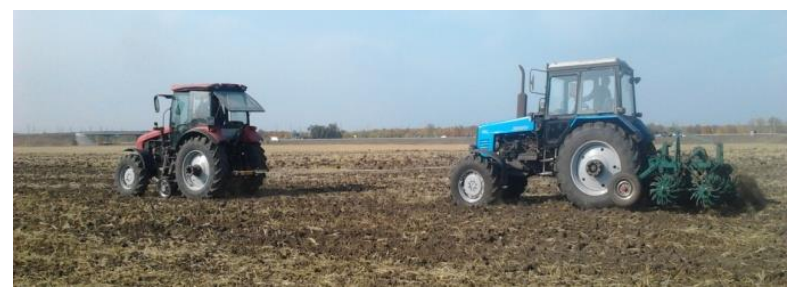

Fig. 4. Conduct an energy assessment by towing

Tractor in neutral gear without implement was towed by another tractor using strain gauge beam for the measuring the rolling resistance. The power to overcome the traction resistance of the implement was determined by towing the unit with the measured implement. Thus experiments were carried out both in the active mode (with the drive of working bodies) and in the passive mode (without the drive of working bodies).

Traction resistance, slipping of the drive wheels and the fuel consumption were determined in accordance with the recommendations of techniques energy estimate [10] by the measuring system IP-264 of FGBU "Povolzskaya state machinery testing station".

Small-sized portable information-measuring system IP-264 (Fig. 5) was used for measurement, analysis, storage and display parameters defining the operational and technological characteristics of tractors and agricultural machines in a convenient form in real time as well as at the end of the experiment.

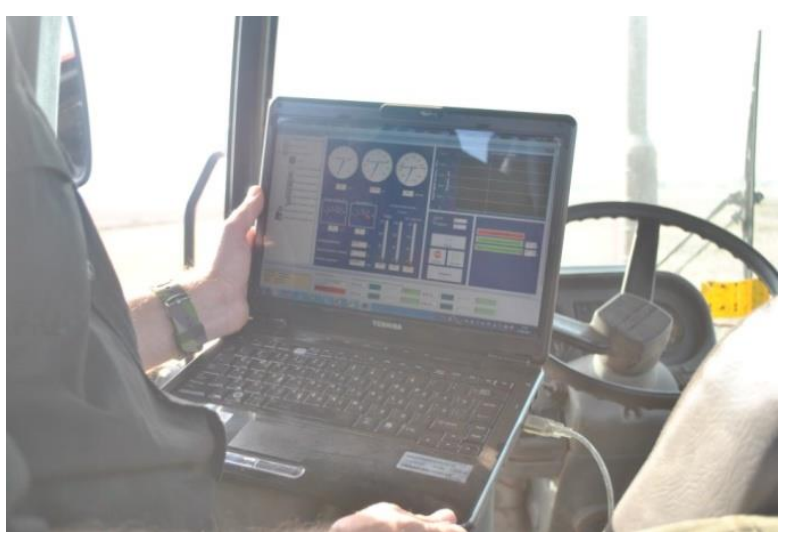

Fig. 5. Portable computer of information-measuring system IP264 with the measurement data acquisition and processing software

Energy performance of traction-drive implements was determined by the strain gauge measurement method in accordance with GOST R 52777-2007. The research conditions were typical for the Middle Volga region late April (table 1).
Table 1. Soil condition during energy estimation

\begin{tabular}{|c|c|c|}
\hline Soil layers, $\mathrm{cm}$ & Soil moisture, & Soil hardness, MPa \\
\hline $0-5$ & 26.3 & 0.05 \\
$5-10$ & 30.1 & 0.17 \\
$10-15$ & 27.4 & 0.26 \\
\hline
\end{tabular}

\section{Results}

According to the results of the energy assessment of the experimental traction-drive tillage implement TPO-3 in spring harrowing over a field tilled by disks since autumn at various speed operating modes (Fig. 6), it can be seen that in the active mode the traction resistance of the implement at all operating tractor speeds being 7.4 to 12 $\mathrm{km} / \mathrm{h}$ was more than $5 \mathrm{kN}$ lower than the traction resistance of the experimental tillage implement in passive mode.

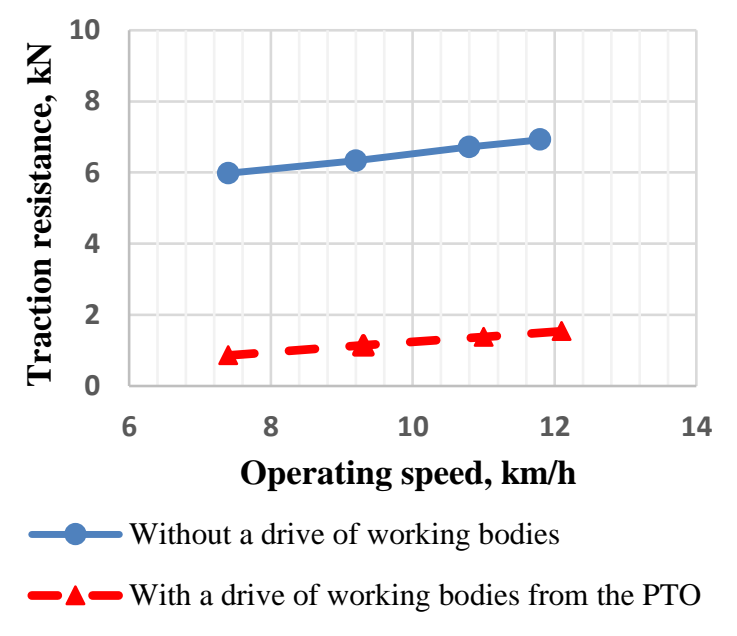

Fig. 6. Graph of change traction resistance experimental traction-drive tillage implement TPO-3, depending on the working speed when working without a drive of working bodies and working bodies driven by the PTO of tractor MTZ 82.1

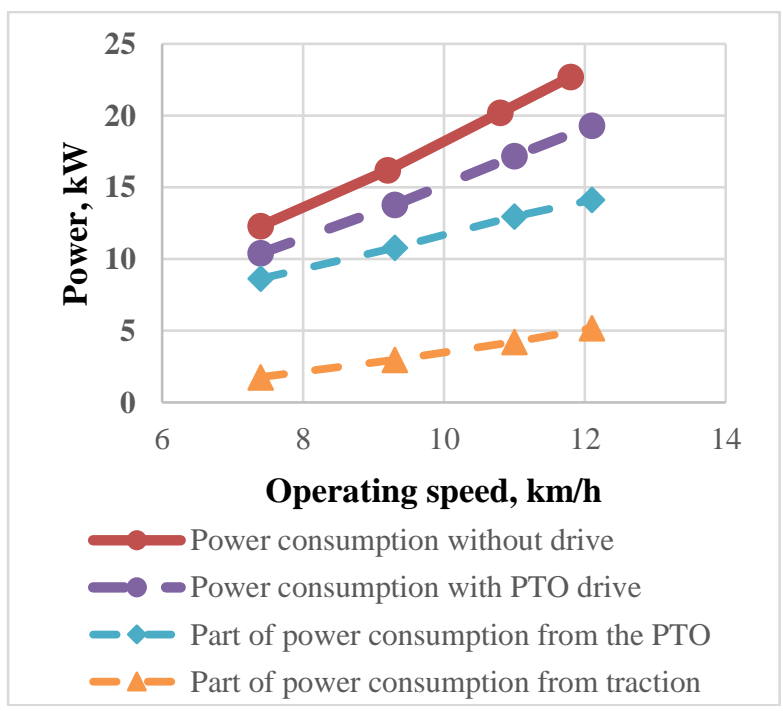

Fig. 7. The graph of change in power consumption by the experimental traction-drive tillage implement TPO-3 depending on the working speed when working without a drive of working bodies and with a drive of working bodies from the PTO of the MTZ-82.1 tractor 
The total power consumption of experimental tractiondrive tillage implement in the active mode was lower passive mode by $15 \%$ (Fig. 6). Power flow distribution ratio in the active mode are as follows: at a speed of $7.4 \mathrm{~km} / \mathrm{h} 83 \%$ of the power directed via the tractor PTO and $17 \%$ via the rod; at a speed of $9.3 \mathrm{~km} / \mathrm{h}-78 \%$ and 22 $\%$ respectively; at a speed of $11 \mathrm{~km} / \mathrm{h}-75 \%$ and $25 \%$ respectively; at a speed of $12.1 \mathrm{~km} / \mathrm{h}-73 \%$ and $27 \%$ respectively.

The graph of fuel flow from the working speed machine-tractor unit with experimental traction-drive tillage implement TPO-3 shows energy efficiency advantage due to the application of traction-drive tillage implement as the most complete (Figure 8). Thus, in the range of operating speeds from 7.4 to $9.3 \mathrm{~km} / \mathrm{h}$, the reduction of hourly fuel consumption is $3.8-4.0 \%$, and in the range of operating speeds from 9.3 to $11.8 \mathrm{~km} / \mathrm{h}$, the reduction of hourly fuel consumption is $5.7-7.4 \%$.

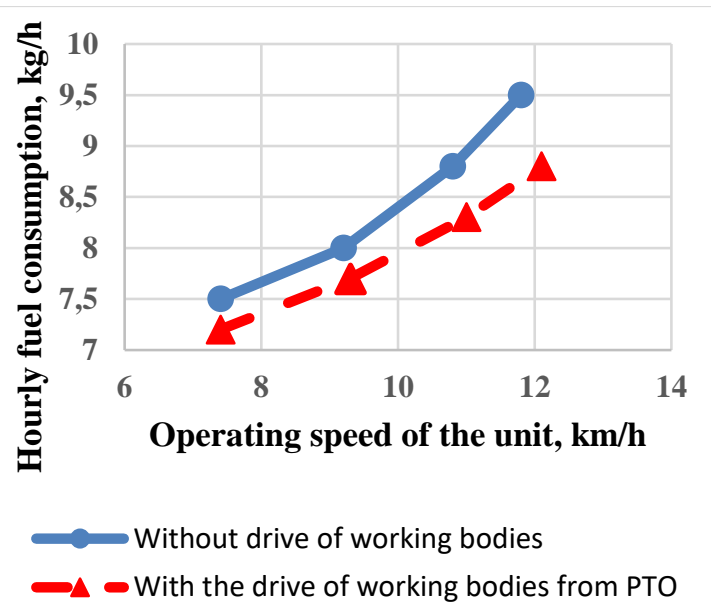

Fig. 8. Dependence of the hourly fuel consumption $(\mathrm{kg} / \mathrm{h})$ on the operating speed $(\mathrm{km} / \mathrm{h})$ of the MTZ-82 tractor in the unit with the experimental traction-drive tillage implements TPO-3

\section{Discussion}

The studies have confirmed that the energy efficiency of the tillage unit depends on how fully the mechanical energy of the tractor engine is converted into mechanical work on loosening the soil. This parameter characterizes the efficiency of the machine-tractor unit. Theoretical calculations have shown that the use of a traction-driven machine-tractor unit can increase the efficiency of it from 21 to $42 \%$ or more, depending on the share of power transmitted via the PTO of the tractor. The experimental prototype traction-drive tillage implement TPO-3 energy performance evaluation allowed recording the reduction of traction resistance of it with $6 \mathrm{kN}$ in the passive mode without the drive to $0.86 \mathrm{kN}$ in active mode driven by a PTO. At the same time, energy consumption for loosening the soil (hourly fuel consumption) decreased by $15 \%$, which confirms the higher energy efficiency of the use of the traction-drive tillage implement in comparison with the traction tillage implementation.

\section{Conclusion}

Tillage energy efficiency improvement can be achieved due to the use of traction-driven tillage implements with active working bodies, not creating high traction resistance and not requiring a large towing weight of the using tractor. The reduction of the traction resistance of such implements can be achieved by transferring the main share of power via the tractor's PTO to the rotary drive working bodies, what creates a pushing force, minimizing the traction resistance of the tillage implement. Higher efficiency of mechanical energy transferred via the PTO compared with the efficiency of the tractor wheels and the reduction of slipping losses allow reducing the hourly fuel consumption when performing early spring soil loosening by $15 \%$. An additional effect may be that the minimum traction resistance of the traction-driven implement allows starting early spring harrowing in the field 2-3 days earlier and save $10-15 \mathrm{~mm}$ more productive moisture in the soil

\section{References}

1. M.N. Chatkin, Kinematics and dynamics of rotary tillers working bodies with screw elements, monograph (2008)

2. P.P. Nalavade, V.M. Salokhe, T. Niyamapa, P. Soni, Performance of free rolling and powered tillage discs, Soil and tillage research (2010)

3. P.P. Nalavade, V.M. Salokhe, T. Niyamapa, P. Soni, Development of a disc harrow for on-farm crop residue management, Int. Agric. Eng. J., 22, 49-60 (2013)

4. R.M. Musin, R.R. Mingalimov, Improved cultivator units with propulsion-rippers, monograph (2012)

5. R.R. Mingalimov, R.M. Musin, Study of the formation and use of an additional driving force of machine-tractor unit as a result of the use of propulsion-rippers, Bull. of the Ulyanovsk SAA, 29, 126-132 (2015)

6. Pat. Russian Federation 2538810. An instrument for surface tillage (2015)

7. F.M. Zoz, R.D. Grisso, Traction and Tractor Performance, Agricult. Equipm. Technol. Conf. (2003)

8. A. Guskov, Determining the towing characteristics of tires of driving wheels of the tractor, Bull. of Kharkiv NAHU, 37, 71-74 (2007)

9. M.A. Petrov, Y. Savelyev, P.A. Ishkin, Improving the efficiency of traction-drive tillage machine, Bull. of the Ulyanovsk SAA, 43, 19-24 (2018)

10. GOST P 52777-2007 Tests agricultural machinery. Methods energy estimate (2008) 